\title{
Avaliação de um programa de intervenção em escolas: Aprender através do jogo
}

\section{RESUMO}

No contexto escolar, o recreio é um dos momentos mais favoráveis para a realização de jogos e atividades de forma voluntária e, consequentemente, para a melhoria das relações sociais e da prática de atividade física. A fim de conhecer a perceção dos alunos em termos de diversidade de jogos no recreio e das interações que aí ocorrem, foi desenhado um estudo quase-experimental de metodologia mista, com uma proposta de intervenção através do jogo, na qual participaram 161 alunos de 6 a 10 anos de uma escola do $1 .^{\circ}$ ciclo da educação básica no norte de Portugal. Para a coleta de dados, utilizou-se preferencialmente um questionário ad hoc, além de notas de campo e gravações em vídeo. Os resultados mostram uma alta participação na proposta por razões de interesse e atratividade, especialmente em rapazes, sendo que os jogos com regras e em grande grupo são os preferidos por ambos os géneros; da mesma forma, é nessas relações intergénero que há um aumento maior, sobretudo nos alunos do último ano. Programas de intervenção lúdica devem ser promovidos para criar oportunidades práticas e diversificar o tipo de jogos praticados pelos alunos na escola.

Palavras-chave: Recreio; Interações sociais; Jogos; Escola básica.

\section{INTRODUÇÃO}

A escola do século XXI deve dar resposta à realidade de hoje e de amanhã, em relação à mudança constante a que a sociedade está sujeita, devido às suas múltiplas transformações nas últimas décadas (Esteve, 2008). Já não se trata de cumprir apenas com a função académica através de um processo de ensino e de aprendizagem orientado exclusivamente para o desenvolvimento das habilidades intelectuais dos alunos; hoje em dia, a escola tem outra função, tão importante ou mais, que é responder à função socializadora (GarcíaLastra, 2013), que para além de contribuir para o acréscimo de conhecimento, também o faça na aquisição de valores, hábitos e outras habilidades que permitam o desenvolvimento integral das crianças com o objetivo de melhor se adaptarem a uma sociedade plural, diversa e heterogénea (Martín-Solbes \& Ruiz-Galacho, 2018).
José Eugenio Rodríguez-

Fernándezi

Universidade

de Santiago de

Compostela, España

Vânia Pereira ${ }^{i i}$

Universidade do Minho, Portugal

Isabel Condessaiii

Universidade dos

Açores, Portugal

Beatriz Pereira ${ }^{\text {iv }}$ Universidade do Minho, Portugal 
A infância é o período ideal para fomentar e promover as relações pessoais. É um bom momento de socialização, aquele onde o ser humano mostra ter uma maior predisposição e flexibilidade para este tipo de aprendizagens e, consequentemente, pelas caraterísticas da natureza da criança, o jogo tende a ser o recurso educativo por excelência para conseguir este fim (Carbonell et al., 2018). Falamos assim do jogo e do seu carácter social, em que as crianças interagem com o ambiente e com outras crianças, para além de ser um ensaio para a vida adulta. Surge deste modo uma das funções mais importantes do jogo na infância, sendo caracterizada por desenvolver estratégias de cooperação e comunicação, com os seus pares e com os adultos, onde manifesta os seus desejos, emoções, necessidades e conquistas, os seus problemas e consequente resolução de conflitos; em definitivo, o seu estado natural e a essência pura do jogo na infância (Meneses \& Monge, 2001).

$\mathrm{Na}$ escola há dois momentos principais em que as crianças entram em contacto com o jogo e, consequentemente, com o impacto que este tem sobre elas. Um desses momentos é na aula de Educação Física, situação que se define pela carga horária semanal (atualmente, em muitos casos, é limitadas a 2h/semana, se considerarmos a Educação Física curricular e as Atividades de Enriquecimento Curricular). Outro desses momentos é o recreio escolar, em que as crianças dispõem de cerca de 30 minutos diários (2h30/semana), que é caraterizado por ser um momento de atividade livre, de participação voluntária, em que criam a sua própria atividade, escolhem com quem a vão partilhar e tomam decisões sobre o início e o fim de cada brincadeira.

Pela sua organização espacial e temporal, o recreio é considerado como o momento mais favorável para que a criança adquira todo o sistema de valores e benefícios de carácter social que são alcançados através do jogo (Fructuoso, 2016; Massey et al., 2018).

0 movimento e a atividade física são o principal resultado do comportamento associado ao tempo e espaço de recreio escolar (Massey et al., 2018). Associado às aulas de Educação Física e às Atividades de Enriquecimento Curricular, o fomento dos recreios ativos é uma boa estratégia para conseguir o objetivo de aumentar o movimento e a atividade física entre os alunos (Martín-Acosta \& Escaravajal, 2019; Méndez-Giménez, 2016;). Desta forma, continuamos a dar respostas paliativas à preocupante situação da saúde infantil (associada ao sobrepeso e à obesidade) a que faz referência a Organização Mundial de Saúde (Organización Mundial de la Salud [OMS], 2010).

Apesar de as crianças realizarem preferencialmente os seus jogos no recreio de forma livre (Rodríguez-Fernández et al., 2019), quando se organizam atividades com a intervenção do adulto, as crianças tendem a desenvolver as suas capacidades e habilidades motoras mais do que o esperado (Wickstrom, 1977), ainda que o papel do adulto esteja sobretudo associado à segurança das crianças (Artavia-Granados, 2014; Massey et al., 2018; Pereira et al., 2017). 0 papel do adulto no recreio deve ser o de proporcionar recursos, novas atividades e a motivação necessária nas crianças, para que estas, posteriormente e de forma autónoma, adquiram uma bagagem de jogos e atividades ampla e variada e para que possam partilhá-la, em determinados momentos, com o docente designado para a supervisão do recreio (controlo e 
segurança) que, de forma voluntária, queira partilhar atividades com os alunos neste momento lúdico.

Partindo da importância do jogo como elemento promotor das relações sociais entre os alunos e que fomenta o movimento e a atividade física, temos por objetivo neste estudo analisar o efeito de uma intervenção realizada no recreio escolar junto de um grupo de alunos, considerando o seu género e ano de escolaridade, tentando preferencialmente:

- $\quad$ perceber porque é que os alunos participaram ou não na intervenção, atendendo às diferenças entre género e ano de escolaridade;

- identificar as interações entre as crianças durante a intervenção, mencionando o sentimento das mesmas relativamente a essas interações, considerando as diferenças entre género e ano de escolaridade;

- verificar a existência, ou não, de alterações provocadas pela intervenção (fases pré, pós-1 e pós-2) no grupo, relativamente ao aumento da diversidade de jogos praticados no recreio pelas crianças, atendendo ao género e ao ano de escolaridade;

- averiguar a existência, ou não, de alterações provocadas pela intervenção (fases pré, pós-1 e pós-2) no grupo, relativamente às interações entre pares, atendendo ao género e ao ano de escolaridade.

\section{METODOLOGIA}

\subsection{AMOSTRA}

Um desenho quase-experimental foi utilizado para este estudo, em que participaram 161 crianças de uma escola do $1^{\circ}$ ciclo do ensino básico do norte de Portugal, com idades compreendidas entre os 6 e os 10 anos, sendo a média de idades de 7,45 \pm 1.15 e havendo uma distribuição semelhante entre rapazes $(n=85)$ e raparigas $(n=76)$. Das 161 crianças, participaram voluntariamente na proposta de jogos no recreio 114 alunos (62 rapazes e 52 raparigas) e um total de 47 crianças (23 rapazes e 24 raparigas) não participaram neste mesmo programa de jogos. Na apresentação dos resultados e para efeitos de anonimato, os nomes dos alunos foram alterados.

\subsection{INSTRUMENTO DE AVALIAÇÃO}

O questionário foi o principal instrumento para coleta de dados, elaborado de acordo com as necessidades do estudo (Fortin, 2006) e depois de realizar uma procura de trabalhos científicos similares. Para sua validação, recorremos a um estudo piloto realizado com outro grupo de crianças, com as mesmas características das que foram selecionadas para este estudo (idade, género e nível de escolaridade). Este questionário (ver em anexo) consistia em dois grandes blocos:

- 10 bloco: Identificação pessoal, escolar e socioeconómica.

- 20 bloco: Intervenção ( 9 questões): sobre a participação em jogos nos recreios nas últimas duas semanas (uma questão dicotômica e uma aberta), sobre a preferência de participação em jogos (uma questão aberta), sobre a interação com os pares (uma questão dicotômica) 
e sobre o gosto de jogar com rapazes/raparigas (uma questão dicotômica e uma aberta). Para completar as informações obtidas nas questões, também foram recolhidas notas de campo durante a observação da intervenção, bem como das gravações realizadas em vídeo sobre as atividades realizadas nos recreios.

\subsection{PROCEDIMENTOS DE RECOLHA E TRATAMENTO DE DADOS}

Para aceder ao campo de estudo, procedemos a várias etapas:

- Pedido de autorização à Direção Geral de Inovação e Desenvolvimento Curricular (DGIDC) para a aplicação do estudo (incluindo o questionário, a intervenção e as filmagens) nas escolas do $1^{0}$ ciclo do ensino básico.

- Pedido formal de aplicação de um estudo com intervenção ao Agrupamento de escolas. Apresentamos também, para essse efeito, a autorização que nos tinha sido dada pela Monitorização de Inquéritos em Meio Escolar (MIME).

- Para a preparação dos intrumentos de investigação e para a seleção dos jogos para a intervenção, foi realizado um estudo piloto com 33 alunos, dos quatro níveis de escolaridade de uma escola do $1^{\mathrm{o}}$ ciclo do ensino básico do concelho de Braga (Portugal). Pretendemos, com este estudo, realizar o levantamento das atividades praticadas nos recreios e das interações que ocorriam durante essas atividades nesse espaço, no sentido de nos auxiliar na construção do questionário que veio a ser utilizado como instrumento no presente trabalho.

- Entramos em contacto com os coordenadores de cada uma das escolas e apresentamos o estudo, explicando todo o proceso que iriamos pôr em prática. Os coordenadores organizaram uma pequena sessão com os professores das respetivas escolas durante o tempo de recreio, onde pudemos expor o estudo que iríamos desenvolver.

- Pedidos de autorizações aos pais explicando o teor do estudo. Todos os alunos levaram para casa o documento e trouxeram-os preenchidos.

- Os investigadores questionaram os alunos sobre a sua vontade de participar no estudo, salvaguardando assim, a liberdade e vontade de participação na criança na investigação (consentimento informado) (Soares, 2006). Assim, informar as crianças acerca dos objetivos é um passo essencial, que deverá assegurar que tais objetivos se traduzam em conhecimento válido acerca dos seus quotidianos, experiências, sentimentos e competências (Soares et al., 2005).

- Aplicação do programa de intervenção (implementação diária nos recreios de um ou dois jogos, durante o período de três semanas).

- Aplicação dos questionários logo após o término do programa de intervenção (na semana imediatamente a seguir à intervenção) (Pós1 ), nas salas de aula, sem interferir na rotina e o trabalho dos professores, submetendo os nossos horários aos deles (Bogdan \& Biklen, 2003).

- Aplicação dos questionários novamente, dois meses e meio após a intervenção (Pós-2). 
As questões fechadas do questionário foram tratadas com o software Statistical Package for the Social Sciences (SPSS) para Windows. As questões abertas foram sujeitas a análise de conteúdo, a partir da qual surgiram as categorías apresentadas nas tabelas apresentadas nos resultados, sendo tratado também com o programa estatístico supracitado. Para a análise dos dados recorremos a estatística descritiva (frequências e percentagens) e comparativa (Qui-Quadrado, com realce para situações diferenciadas. 0 valor da significância foi definito como $\mathrm{p}<0,05$ ).

\section{RESULTADOS}

Na Tabela 1 destacamos que, em pelo menos um dos jogos propostos nesta intervenção, participaram 114 dos 161 alunos da escola. Consideramos que a adesão à intervenção foi bem sucedida, pois tivemos $70,8 \%$ dos alunos da escola a participarem na mesma. Apesar da não existência de diferenças significativas, quem mais participou na intervenção, atendendo ao género, foram os rapazes e, quanto ao ano, foram as crianças dos $1^{\mathrm{o}}$ e $2^{\mathrm{o}}$ anos de escolaridade.

Tabela 1

Participação das crianças do grupo de intervenção (G.I.) nos jogos propostos: Diferenças entre género e ano de escolaridade

\begin{tabular}{|c|c|c|c|c|c|c|c|c|c|}
\hline \multirow{2}{*}{\multicolumn{2}{|c|}{$\begin{array}{r}\text { Participaçào } \\
\text { nos jogos }\end{array}$}} & \multicolumn{2}{|c|}{ Género } & \multirow{3}{*}{$\begin{array}{c}\begin{array}{c}\text { Total } \\
\mathrm{n}=161\end{array} \\
47\end{array}$} & \multirow{2}{*}{$\mathbf{P}$} & \multicolumn{2}{|c|}{ Ano de escolaridade } & \multirow{3}{*}{$\begin{array}{c}\begin{array}{c}\text { Total } \\
\mathbf{n}=161\end{array} \\
47\end{array}$} & \multirow{2}{*}{$\mathbf{P}$} \\
\hline & & $\delta$ & 9 & & & $1^{\circ} \times 2^{\circ}$ ano & $3^{\circ}$ e $4^{\circ}$ ano & & \\
\hline Vัมีด & $\mathbf{n}$ & 23 & 24 & & \multirow{4}{*}{ NS } & 20 & 27 & & \multirow{4}{*}{ NS } \\
\hline Nato & $\%$ & 27,1 & 31,6 & 29,2 & & 23,8 & 35,1 & 29,2 & \\
\hline \multirow{2}{*}{ Sim } & $\mathbf{n}$ & 62 & 52 & 114 & & 64 & 50 & 114 & \\
\hline & $\%$ & 72.9 & 68,4 & 70,8 & & 76,2 & 64,9 & 70.8 & \\
\hline \multirow{2}{*}{ Total } & $\mathbf{n}$ & 85 & 76 & 161 & & 84 & 77 & 161 & \\
\hline & $\%$ & 100,0 & 100.0 & 100.0 & & 100,0 & 100.0 & 100.0 & \\
\hline
\end{tabular}

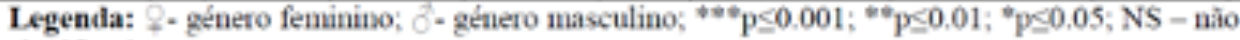
significativo

Analisando a Tabela 2, destacamos que cerca de 40\% dos alunos participaram em um ou dois jogos, $30 \%$ participaram em três ou mais jogos e aproximadamente $30 \%$ dos alunos não participaram em nenhum jogo. Salientamos ainda as diferenças entre género no que se refere à permanência no programa de intervenção, pois, como podemos observar, a maioria dos rapazes $(45,8 \%)$ participou apenas em um ou dois jogos, enquanto a maioria das raparigas $(35,2 \%)$ participou em três ou mais jogos, sendo que $14,9 \%$ destas participaram em onze ou mais jogos propostos na intervenção e apenas $8,4 \%$ dos rapazes o fizeram, não existindo, no entanto, diferenças significativas quanto ao género.

Já quanto ao ano de escolaridade, podemos verificar diferenças significativas $(\mathrm{p} \leq 0,01)$, uma vez que foram mais as crianças dos $1^{\circ}$ e $2^{\circ}$ anos (75\%) que participaram na intervenção do que as crianças dos $3^{\circ}$ e $4^{\circ}$ anos (65\%). Estas últimas participaram, principalmente, em um ou dois jogos da intervenção $(48,1 \%)$, enquanto as crianças mais novas participaram, 
maioritariamente, em três ou mais jogos $(43,8 \%)$, tendo estas estado mais presentes em toda a intervenção, pois $15,0 \%$ participaram em onze ou mais jogos, enquanto das crianças mais velhas foram apenas 7,8\% a fazê-lo.

Tabela 2

Quantidade de jogos em que participaram as crianças do G.I.: Diferenças entre género e ano de escolaridade

\begin{tabular}{|c|c|c|c|c|c|c|c|c|c|}
\hline \multirow{2}{*}{$\begin{array}{c}\text { Em quantos } \\
\text { jogos participou? }\end{array}$} & & \multicolumn{2}{|c|}{ Género } & \multirow{2}{*}{ Total } & \multirow[b]{2}{*}{ p } & \multicolumn{2}{|c|}{$\begin{array}{c}\text { Ano de } \\
\text { escolaridade }\end{array}$} & \multirow{2}{*}{ Total } & \multirow[b]{2}{*}{$\mathbf{p}$} \\
\hline & & $\partial$ & $q$ & & & $\begin{array}{l}1^{\circ} \text { e } 2^{\circ} \\
\text { ano }\end{array}$ & $\begin{array}{l}3^{\circ} \times 4^{*} \\
\text { ano }\end{array}$ & & \\
\hline \multirow{2}{*}{ Nenhum } & $\mathbf{n}$ & 23 & 24 & 47 & \multirow{10}{*}{ NS } & 20 & 27 & 47 & \multirow{10}{*}{$\because=0,006$} \\
\hline & $\%$ & 27,7 & 32,4 & 29,9 & & 25,0 & 35,1 & 29,9 & \\
\hline \multirow{2}{*}{$1-2$} & $\mathrm{n}$ & 38 & 24 & 62 & & 25 & 37 & 62 & \\
\hline & $\%$ & 45.8 & 32.4 & 39.5 & & 31.3 & 48.1 & 39.5 & \\
\hline \multirow{2}{*}{$3-5$} & $\mathrm{n}$ & 10 & 11 & 21 & & 15 & 6 & 21 & \\
\hline & $\%$ & 12.0 & 14,9 & 13,4 & & 18,8 & 7,8 & 13,4 & \\
\hline \multirow{2}{*}{$6-10$} & $\mathrm{n}$ & 5 & 4 & 9 & & 8 & 1 & 9 & \\
\hline & $\%$ & 6,0 & 5,4 & 5,7 & & 10,0 & 1,3 & 5,7 & \\
\hline \multirow{2}{*}{$11-15$} & $\mathbf{n}$ & 7 & 11 & 18 & & 12 & 6 & 18 & \\
\hline & $\%$ & 8,4 & 14,9 & 11.5 & & 15.0 & 7,8 & 11,5 & \\
\hline \multirow{2}{*}{ Total } & $\mathrm{n}$ & 83 & 74 & 157 & & 80 & 77 & 157 & \\
\hline & $\%$ & 100,0 & 100.0 & 100 & & 100,0 & 100,0 & 100,0 & \\
\hline
\end{tabular}

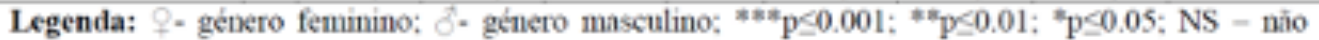
significativo

A Tabela 3 reflete os motivos pelos quais as crianças participaram nos jogos aplicados no recreio. Assim, a maioria das crianças $(75,9 \%)$ participou nos jogos por considerá-los interessantes e divertidos, 14,9\% participaram para aprender novos jogos e brincar com outras crianças, e só uma minoria $(9,2 \%)$ fez parte da intervenção porque não tinha mais nada para fazer. Apesar de ser uma minoria, devemos ter em conta que estes casos podem ser de crianças que estão um pouco à margem no recreio, são as crianças que normalmente se isolam no recreio, ou que são rejeitadas pelos seus pares. Ao participarem em jogos com outras crianças, sentem-se valorizadas e sentem que fazem parte do grupo, socializam e jogam.

Tabela 3

Motivos pelos quais as crianças do G.l. participaram nos jogos: Diferenças entre género e ano de escolaridade

\begin{tabular}{|c|c|c|c|c|c|c|c|c|c|}
\hline \multirow{2}{*}{\multicolumn{2}{|c|}{$\begin{array}{c}\text { Porque participaram } \\
\text { nos jogos? }\end{array}$}} & \multicolumn{2}{|c|}{ Género } & \multirow{2}{*}{ Total } & \multirow{2}{*}{$\mathbf{p}$} & \multicolumn{2}{|c|}{ Ano de escolaridade } & \multirow{2}{*}{ Total } & \multirow{2}{*}{$\mathbf{P}$} \\
\hline & & $\delta$ & 웅 & & & $1^{\circ} \in 2^{*}$ & $3^{\circ}$ e $4^{*}$ & & \\
\hline \multirow{2}{*}{$\begin{array}{c}\text { Jogos } \\
\text { interessantes e } \\
\text { divertidos }\end{array}$} & $\mathrm{n}$ & 36 & 30 & 66 & \multirow{6}{*}{ NS } & 35 & 31 & 66 & \multirow{8}{*}{ NS } \\
\hline & $\%$ & 76,6 & 75,0 & 75,9 & & 76,1 & 75,6 & 75,9 & \\
\hline \multirow{2}{*}{$\begin{array}{l}\text { Aprender novos } \\
\text { jogos e brincar } \\
\text { com outros } \\
\text { meninos }\end{array}$} & $\mathrm{n}$ & 7 & 6 & 13 & & 8 & 5 & 13 & \\
\hline & $\%$ & 14,9 & 15,0 & 14,9 & & 17.4 & 12.2 & 14.9 & \\
\hline \multirow{2}{*}{$\begin{array}{c}\text { Não tinha nada } \\
\text { para fazer }\end{array}$} & $\mathrm{n}$ & 4 & 4 & 8 & & 3 & 5 & 8 & \\
\hline & $\%$ & 8.5 & 10.0 & 9.2 & & 6.5 & 12.2 & 9.2 & \\
\hline \multirow{2}{*}{ Total } & $\mathbf{n}$ & 47 & 40 & 87 & & 46 & 41 & 87 & \\
\hline & $\%$ & 100,0 & 100,0 & 100,0 & & 100,0 & 100,0 & 100,0 & \\
\hline
\end{tabular}

Legenda: - género feminino; - género masculino; "*" $\mathrm{p} \leq 0.001 ;{ }^{*} \mathrm{p} \leq 0.01 ; " \mathrm{p} \leq 0.05$; NS - não sienificativo 
A Tabela 4 mostra os motivos que levaram os alunos a não participar nos jogos propostos na intervenção. Percebemos que a maioria das crianças que não participou fez devido ao facto de preferir as suas brincadeiras de recreio com os seus amigos (55,6\%), enquanto para $30,6 \%$ das crianças o motivo foi, simplesmente, "não me apeteceu", e para 13,9\% foi o facto de já conhecerem os jogos. Não se registaram diferenças significativas em relação ao género, nem em relação ao ano de escolaridade.

Tabela 4

Motivos Motivos pelos quais as crianças do G.l. não participaram nos jogos:

Diferenças entre género e ano de escolaridade

\begin{tabular}{|c|c|c|c|c|c|c|c|c|c|}
\hline \multirow{2}{*}{$\begin{array}{c}\text { Porque nào } \\
\text { participaram nos } \\
\text { jogos? }\end{array}$} & & \multicolumn{2}{|c|}{ Género } & \multirow{2}{*}{$\begin{array}{l}\text { Total } \\
\mathbf{n}=36\end{array}$} & \multirow[b]{2}{*}{$\mathrm{p}$} & \multicolumn{2}{|c|}{$\begin{array}{c}\text { Ano de } \\
\text { escolaridade }\end{array}$} & \multirow{2}{*}{$\begin{array}{l}\text { Total } \\
\mathrm{n}=36\end{array}$} & \multirow[b]{2}{*}{ p } \\
\hline & & $\mathrm{n}=17$ & $\begin{array}{l}9 \\
n=19\end{array}$ & & & $\begin{array}{l}1^{\circ} \times 2^{\circ} \\
\mathrm{n}=11\end{array}$ & $\begin{array}{l}3^{\circ} \text { e } 4^{\circ} \\
n=25\end{array}$ & & \\
\hline \multirow{2}{*}{$\begin{array}{l}\text { Prefiro as minhas } \\
\text { brincadeiras com } 0 s \\
\text { meus amigos }\end{array}$} & $\mathbf{n}$ & 10 & 10 & 20 & \multirow{6}{*}{ NS } & 7 & 13 & 20 & \multirow{6}{*}{ NS } \\
\hline & $\%$ & 58.8 & 52.6 & 55,6 & & 63,6 & 52,0 & 55.6 & \\
\hline \multirow{2}{*}{ Nà me apeteceu } & $\mathbf{n}$ & 5 & 6 & 11 & & 4 & 7 & 11 & \\
\hline & $\%$ & 29,4 & 31,6 & 30,6 & & 36,4 & 28,0 & 30.6 & \\
\hline \multirow{2}{*}{ Já conhexia os jogos } & $\mathbf{n}$ & 2 & 3 & 5 & & 0 & 5 & 5 & \\
\hline & $\%$ & 11.8 & 15,8 & 13.9 & & 0.0 & 20,0 & 139 & \\
\hline \multirow{2}{*}{ Total } & $\mathbf{n}$ & 17 & 19 & 36 & & 11 & 25 & 36 & \\
\hline & $\%$ & 100.0 & 100.0 & 100.0 & & 100.0 & 100.0 & 100.0 & \\
\hline
\end{tabular}

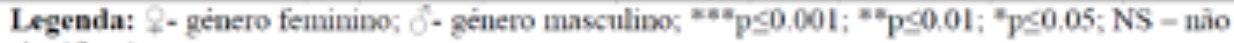
significativo

Na Tabela 5 apresentamos os jogos que as crianças preferiram realizar na fase de intervenção. Destacamos o jogo "futebol sem bola" como sendo o mais preferido pelas crianças, seguindo-se o jogo do "camaleão" e, em terceiro lugar, o jogo "barra do lenço". Quanto ao género, é notório que os rapazes $(41,5 \%)$ gostam mais do "futebol sem bola" do que as raparigas $(21,4 \%)$; em contrapartida, mais raparigas do que rapazes preferem os jogos do "camaleão" (+12,5\%) e "barra do lenço" (+6,8\%). Não existem diferenças significativas em relação ao género quanto aos jogos preferidos.

No entanto, em relação ao ano de escolaridade, existem diferenças significativas $(\mathrm{p} \leq 0,000)$. Para $53,2 \%$ das crianças dos $3^{\circ}$ e $4^{\circ}$ anos o jogo de que mais gostaram foi o "futebol sem bola" e apenas 12,5\% das crianças dos $1^{\circ}$ e $2^{\circ}$ anos o referiram como jogo preferido. 0 segundo jogo preferido pelas crianças mais velhas foi o jogo do "stop" $(17,0 \%)$ e o terceiro jogo que mais gostaram de fazer foi o jogo do "camaleão" $(12,8 \%)$. Este último é o jogo mais apreciado pelas crianças mais novas, dos $1^{\circ}$ e $2^{\circ}$ anos $(41,7 \%)$, e na posição seguinte encontram-se três jogos: "barra do lenço", "futebol sem bola" e "passarão", todos com a mesma percentagem $(12,5 \%)$.

De uma forma geral, se contabilizarmos o total dos jogos dentro de cada categoria, podemos destacar que os "jogos de regras" são os mais preferidos pelas crianças dos 3o e $4^{\circ}$ anos $(78,7 \%)$, enquanto os "jogos populares" $(64,7 \%)$ são os mais escolhidos pelos alunos dos $1^{\circ}$ e $2^{\circ}$ anos de escolaridade. 
Tabela 5

Jogos da intervenção (avaliação da intervenção Pós 1) que as crianças preferiram realizar: Diferenças entre género e ano de escolaridade

\begin{tabular}{|c|c|c|c|c|c|c|c|c|c|c|}
\hline & \multirow{2}{*}{\multicolumn{2}{|c|}{ Jogos preferides }} & \multicolumn{2}{|c|}{ Género } & \multirow{2}{*}{ Total } & \multirow{2}{*}{$\mathbf{p}$} & \multicolumn{2}{|c|}{$\begin{array}{c}\text { Ano de } \\
\text { escolaridade }\end{array}$} & \multirow{2}{*}{ Total } & \multirow{2}{*}{$\mathbf{P}$} \\
\hline & & & 8 & $q$ & & & $1^{*} \in 2^{*}$ & $3^{*} \in 4^{*}$ & & \\
\hline \multirow{2}{*}{ 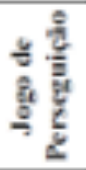 } & \multirow{2}{*}{ Escondidas } & $\mathbf{a}$ & 2 & 1 & 3 & \multirow{24}{*}{ NS } & 3 & 0 & 3 & \multirow{22}{*}{${ }^{\circ} 0,000$} \\
\hline & & 90 & 3,8 & 2,4 & 3.2 & & 6,3 & 0,0 & 3.2 & \\
\hline \multirow{10}{*}{ 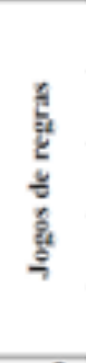 } & \multirow{2}{*}{ Bola queima } & $\mathbf{n}$ & 0 & 1 & 1 & & 1 & 0 & 1 & \\
\hline & & 40 & 0.0 & 2.4 & 1.1 & & 2,1 & 0.0 & 1.1 & \\
\hline & \multirow{2}{*}{ Stop } & $\mathbf{n}$ & 6 & 2 & 8 & & 0 & 8 & 8 & \\
\hline & & 40 & 11.3 & 4.8 & 8.4 & & 0.0 & 17.0 & 8,4 & \\
\hline & \multirow{2}{*}{ Jogo do mata } & $\mathbf{n}$ & 0 & 1 & 1 & & 1 & 0 & 1 & \\
\hline & & 90 & 0.0 & 2.4 & 1.1 & & 2.1 & 0.0 & 1.1 & \\
\hline & \multirow{2}{*}{$\begin{array}{c}\text { Barra do } \\
\text { lesco }\end{array}$} & $\mathbf{n}$ & 4 & 6 & 10 & & 6 & 4 & 10 & \\
\hline & & 96 & 7.5 & 14.3 & 10.5 & & 12.5 & 8.5 & 10.5 & \\
\hline & \multirow{2}{*}{$\begin{array}{c}\text { Fatebol sem } \\
\text { bola }\end{array}$} & $\mathbf{n}$ & 22 & 9 & 31 & & 6 & 25 & 31 & \\
\hline & & 90 & 41.5 & 21.4 & 32,6 & & 12.5 & 53.2 & 32.6 & \\
\hline \multirow{2}{*}{ 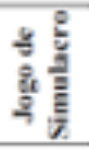 } & \multirow{2}{*}{ Faz de conta } & $\mathbf{n}$ & 2 & 0 & 2 & & 0 & 2 & 2 & \\
\hline & & 96 & 3.8 & 0.0 & 2.1 & & 0,0 & 4,3 & 2.1 & \\
\hline \multirow{10}{*}{ 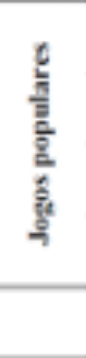 } & \multirow{2}{*}{ Camaleate } & $\mathbf{n}$ & 11 & 15 & 26 & & 20 & 6 & 26 & \\
\hline & & $\%$ & 20.8 & 33,3 & 27,4 & & 41.7 & 12.8 & 27.4 & \\
\hline & \multirow{2}{*}{$\begin{array}{c}\text { Macaquinho } \\
\text { Chinês }\end{array}$} & $\mathbf{n}$ & 3 & 1 & 4 & & 3 & 1 & 4 & \\
\hline & & 90 & 5.7 & 2.2 & 4.2 & & 6.3 & 2.1 & 4.2 & \\
\hline & \multirow{2}{*}{ Passaràe } & $\mathbf{n}$ & 2 & 5 & 7 & & 6 & 1 & 7 & \\
\hline & & 90 & 3.8 & 11,1 & 7,4 & & 12.5 & 2,1 & 7,4 & \\
\hline & \multirow{2}{*}{ Rei manda } & $\mathbf{n}$ & 1 & 1 & 2 & & 2 & 0 & 2 & \\
\hline & & 90 & 1.9 & 2.4 & 2.1 & & 4.2 & 0.0 & 2.1 & \\
\hline & \multirow{2}{*}{ Total } & $\mathbf{n}$ & 53 & 42 & 95 & & 48 & 47 & 95 & \\
\hline & & 90 & 100.0 & 100,0 & 100.0 & & 100.0 & 100.0 & 100,0 & \\
\hline
\end{tabular}
significativo

Durante a intervenção, praticamente todas as crianças $(96,3 \%)$ interagiram com outras crianças com quem, habitualmente, não costumavam interagir, como podemos confirmar na Tabela 6 , demonstrando assim que durante esta intervenção as crianças puderam experimentar diferentes tipos de interações: com crianças mais velhas, mais novas, do sexo oposto, de outras turmas. Ao diversificarem as suas interações, as crianças estão a desenvolver mecanismos sociais e de comunicação que lhes serão úteis no dia a dia, na sua ligação com os outros (adultos ou crianças), e ainda as prepara para a sua vida social na adolescência e na idade adulta. 
Tabela 6

Socialização do G.l., durante a intervenção, com crianças com quem, habitualmente não interagiam no recreio: Diferenças entre género e ano de escolaridade

\begin{tabular}{|c|c|c|c|c|c|c|c|c|c|}
\hline \multirow{2}{*}{\multicolumn{2}{|c|}{$\begin{array}{l}\text { Iuterações com outras } \\
\text { crianças durante a } \\
\text { intervençino }\end{array}$}} & \multicolumn{2}{|c|}{ Género } & \multirow[t]{2}{*}{ Total } & \multirow{2}{*}{ p } & \multicolumn{2}{|c|}{$\begin{array}{c}\text { Ano de } \\
\text { escolaridade }\end{array}$} & \multirow[t]{2}{*}{ Total } & \multirow{2}{*}{ p } \\
\hline & & 8 & q & & & $1^{\circ} \in 2^{\circ}$ & $3^{\circ}<4^{\circ}$ & & \\
\hline \multirow{2}{*}{ No } & n & 2 & 2 & 4 & \multirow{4}{*}{ NS } & 3 & 1 & 4 & \multirow{4}{*}{ NS } \\
\hline & $0_{6}$ & 3,3 & 4.1 & 3.7 & & 1.9 & 2.1 & 3.7 & \\
\hline \multirow{2}{*}{ Siın } & n & 58 & 47 & 105 & & 58 & 47 & 105 & \\
\hline & $\theta_{i}$ & 96.7 & 95,9 & 96,3 & & 95,1 & 97,9 & 96.3 & \\
\hline \multirow{2}{*}{ Total } & n & 60 & 49 & 109 & & 61 & 48 & 109 & \\
\hline & $\theta_{0}$ & 100,0 & 100,0 & 100.0 & & 100.0 & 100.0 & 100,0 & \\
\hline
\end{tabular}

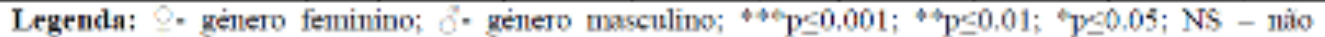
siguificativo

A Tabela 7 mostra que a grande maioria das crianças $(88,5 \%)$ afirmou ter gostado de interagir, durante os jogos, com crianças com quem não costumava jogar, não havendo diferenças significativas relativamente ao género. Quanto ao ano de escolaridade, existem diferenças significativas a registar, pois as crianças mais velhas gostaram todas dessa interação com outros pares, enquanto para $21,1 \%$ das crianças mais novas, dos $1^{\circ}$ e $2^{\circ}$ anos, essa interação não foi tão positiva.

Mesmo assim, apesar de a maioria das crianças dos $1^{\mathrm{o}}$ e $2^{\mathrm{o}}$ anos ter gostado da interação com crianças com quem habitualmente não interage, o que é facto é que nestas idades (6-7 anos) as crianças necessitam de se sentir seguras e os seus amigos de todos os dias são a sua segurança, daí esta poder ser uma possível explicação para essas crianças não aceitarem facilmente outras crianças no seu grupo de jogo.

Tabela 7

Satisfação do G.I. por interagir com outras crianças com quem não interagiam habitualmente no recreio: Diferenças entre género e ano de escolaridade

\begin{tabular}{|c|c|c|c|c|c|c|c|c|c|}
\hline \multirow{2}{*}{\multicolumn{2}{|c|}{$\begin{array}{l}\text { Gostaste de jogar } \\
\text { com essas crianças? }\end{array}$}} & \multicolumn{2}{|c|}{ Gencro } & \multirow[b]{2}{*}{ Total } & \multirow[b]{2}{*}{$\mathrm{p}$} & \multicolumn{2}{|c|}{ Ano de cscolaridade } & \multirow[b]{2}{*}{ Total } & \multirow[b]{2}{*}{ p } \\
\hline & & t & $\varphi$ & & & $\begin{array}{c}1^{*} \times 2^{*} \\
\text { ano }\end{array}$ & $\begin{array}{c}3^{2} \mathrm{e}^{\circ} \\
\text { ano }\end{array}$ & & \\
\hline \multirow{2}{*}{ Nĩ̄ } & 口 & 5 & 7 & 12 & \multirow{6}{*}{$\mathrm{NS}$} & 12 & 0 & 12 & \multirow{6}{*}{${ }^{4} 0,000$} \\
\hline & $u_{i}$ & 8,5 & 15,6 & 11,5 & & 21,1 & 0,0 & 11,5 & \\
\hline \multirow{2}{*}{ Sim } & $\mathbf{n}$ & 54 & 38 & 92 & & 45 & 47 & 92 & \\
\hline & $u_{i}$ & 91.5 & 81.4 & 88.5 & & 78,9 & 100.0 & 88,5 & \\
\hline \multirow{2}{*}{ Total } & $\mathbf{0}$ & 59 & 45 & 104 & & 57 & 47 & 104 & \\
\hline & 96 & 100,0 & 100,0 & 100,0 & & 100,0 & 100,0 & 100,0 & \\
\hline
\end{tabular}

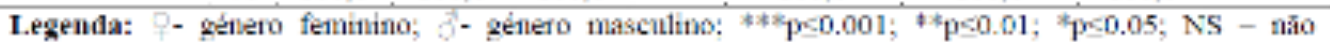
siguilicalivo

Esclarecemos que, nos dados da Tabela 8, não foram considerados os alunos do $1^{\circ}$ ano, uma vez que estes ainda não possuíam competências de escrita para responder às questões que deram origem ao respetivo quadro. Assim, na Tabela 8 vemos que o principal motivo apresentado pelas crianças para justificarem o facto de terem gostado de jogar com outros pares, com quem não estavam habituadas a jogar, foi pelo prazer e diversão que daí obtiveram ("Foi divertido"); foram mais as raparigas a mencionar este motivo e, 
quanto ao ano de escolaridade, foi o $2^{\circ}$ ano, apesar de não se registarem diferenças significativas nem quanto ao género, nem quanto ao ano de escolaridade. "Conheceram outras crianças da escola" foi o segundo motivo apresentado por ambos os géneros e anos de escolaridade. Ainda alguns alunos referiram que nessas interações "sentiram-se incluídos nos jogos".

Em relação ao facto de não terem gostado de jogar com alguns/algumas rapazes/raparigas, apenas seis alunos do $2^{\circ}$ ano de escolaridade mencionaram os motivos para justificar a sua resposta: "esses meninos aborrecem-me" (Cátia, 7 anos); "não têm piada" (Ivo, 7 anos, e Eduardo, 8 anos); "eram batoteiros" (Alexandre, 7 anos); "não gostei de brincar com eles porque já tenho amigos" (Rui, 7 anos); “eram muitos” (Joana, 8 anos).

Tabela 8

Motivos pelos quais o G.I. gostou de jogar com crianças com quem nunca tinha interagido: Diferenças entre género e ano de escolaridade

\begin{tabular}{|c|c|c|c|c|c|c|c|c|c|c|}
\hline \multirow{2}{*}{\multicolumn{2}{|c|}{$\begin{array}{l}\text { Porquue gostasie de } \\
\text { jogar com essas } \\
\text { crlanças" }\end{array}$}} & \multicolumn{2}{|c|}{ Genero } & \multirow{2}{*}{ Total } & \multirow[b]{2}{*}{$\mathrm{p}$} & \multicolumn{3}{|c|}{ Amo de escolaridade } & \multirow{2}{*}{ Total } & \multirow[b]{2}{*}{ p } \\
\hline & & 8 & 9 & & & $2^{*}$ ano & $3^{\circ}$ ano & $4^{\circ}$ ano & & \\
\hline \multirow{2}{*}{ Foi diverliulo } & n & 21 & 17 & 38 & \multirow{6}{*}{ NS } & 15 & 10 & 13 & 38 & \multirow{6}{*}{ NS } \\
\hline & 96 & 51,2 & 65,4 & 56,7 & & 57,7 & 55.5 & 56,6 & 56,7 & \\
\hline \multirow{2}{*}{$\begin{array}{l}\text { Conbeccram } \\
\text { outras } \\
\text { crianças da } \\
\text { escolı }\end{array}$} & $\mathbf{n}$ & 16 & 8 & 24 & & 10 & 5 & 9 & 24 & \\
\hline & $\%$ & 39,0 & 30,8 & 35,8 & & 38,5 & 27,8 & 39,1 & 35,8 & \\
\hline \multirow{2}{*}{$\begin{array}{l}\text { Seutiram-se } \\
\text { incluilos (as) } \\
\text { nos jogos }\end{array}$} & n & 4 & 1 & 5 & & 1 & 3 & 1 & 5 & \\
\hline & $\%$ & 9.8 & 3.8 & 7.5 & & 3.8 & 16.7 & 4,3 & 7,5 & \\
\hline \multirow{2}{*}{ Total } & n & 41 & 26 & 67 & & 26 & 18 & 23 & 67 & \\
\hline & $a / 6$ & 100,0 & 100.0 & 100,0 & & 100,0 & 100,0 & 100,0 & 100,0 & \\
\hline
\end{tabular}

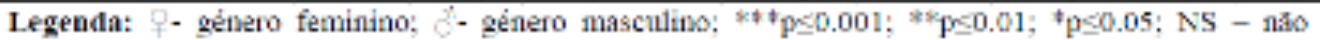
sigmilicativo

Passados três meses da intervenção, verificámos que, apesar de poucas ocorrências, alguns dos jogos aplicados na intervenção ainda eram jogados por algumas crianças. Desta forma, através da análise às questões do teste, nomeadamente às questões "Participaste em jogos no recreio nas últimas duas semanas?" e "Qual foi o jogo em que mais gostaste de participar?", pudemos verificar que, na fase pós-2, algumas crianças mencionaram como jogos preferidos no recreio alguns dos jogos que tinham sido introduzidos na intervenção: "futebol sem bola" (mencionado por dois rapazes do 4ํo ano); "jogo do mata" (mencionado por dois rapazes, um do $2^{\circ}$ ano e outro do $3^{\circ}$ ano); "faz de conta" (mencionado por um rapaz do $2^{\circ}$ ano); "rei manda" (referido por uma rapariga do $2^{\circ}$ ano); "escondidas" (referido por três raparigas, duas do $2^{\circ}$ ano e uma do $4^{\circ}$ ano, e por um rapaz do $3^{\circ}$ ano); “camaleão" (referido por quatro rapazes, dois do $2^{\circ}$ ano e dois do $3^{\circ}$ ano, e por uma rapariga do $4^{\circ}$ ano).

Quanto às interações entre pares no recreio, 107 crianças responderam que brincaram com colegas com quem não costumavam brincar, enquanto na fase pós-2 (três meses após a intervenção) esse número decresceu, pois apenas 27 crianças afirmaram ter jogado com outras crianças com quem, normalmente, não costumavam jogar. 


\section{DISCUSSÃO}

Há uma forte ligação entre o jogo e o desenvolvimento das capacidades sociais da criança (Bodrova \& Leong, 2005; Jover et al., 2018; Gallardo \& Gallardo, 2018). Neste estudo, essa ligação parece evidente, pois foi através de uma intervenção ao nível da aplicação de jogos no recreio que provocámos alterações nos comportamentos sociais das crianças, principalmente no aumento das interações entre rapazes e raparigas da turma.

Durante a intervenção as crianças jogaram e lidaram com crianças com quem não costumavam interagir, tendo a maioria considerado esse facto divertido; alguns alunos mencionaram que conheceram outras crianças da escola, e ainda uma minoria referiu ter gostado dessas interações porque se sentiram incluídos nos jogos. Há estudos onde se verificou que algumas crianças não gostavam do recreio por serem rejeitadas pelos seus pares (Olweus, 1993; Pereira, 2001, 2008; Pereira et al., 2009; Rodríguez-Fernández et al., 2019). Neste contexto, o jogo e a brincadeira introduzidos e mediados no recreio da escola, com clara intenção pedagógica, podem ser fatores preponderantes para o bem-estar de todos os alunos (Farenzena et al., 2012; Pereira et al., 1997; Rimaicuna, 2014).

Consideramos que esta intervenção foi positiva para os que se divertiram e aprenderam outros jogos, aumentando as possibilidades de escolha de jogos no recreio e, consequentemente, aumentando assim o seu repertório motor (Pereira et al., 2018). Também foi positiva para os que socializaram com outras crianças como nunca o tinham feito, pois aumentaram a sua rede de socialização, permitindo-se aprender com os outros a negociar, a interagir e a resolver situações de conflito (Castillo-Rodríguez et al., 2018; López-Ros \& Eberle, 2003; Pereira et al., 2017). E ainda para a minoria que se aproximou da intervenção e que jogou jogos de grupo no recreio (alguns pela primeira vez), dando o primeiro passo para conhecer e interagir com outras crianças, quebrando o "silêncio" e o isolamento.

Normalmente, a criança envolve-se em jogos que considera prazerosos, imaginativos e socialmente interativos (Delgado, 2011; Lester \& Russell, 2011; Otálvaro, 2011). Desta forma, julgamos ter atingido o nosso objetivo quanto à adesão à intervenção realizada neste estudo, já que, não sendo uma intervenção obrigatória, a maioria das crianças participou na intervenção, justificando essa participação devido ao facto de os jogos serem interessantes e divertidos, assim como ser uma forma de aprender novos jogos com outros rapazes e raparigas.

Todas as crianças tinham liberdade de escolha em relação à intervenção, pois esta não era obrigatória. Todos os argumentos utilizados pelas crianças são legítimos, pois é o seu tempo de recreio que está aqui em causa; é que enquanto uns aderiram e se divertiram participando na intervenção, outros preferiram não o fazer pelos motivos anteriormente referidos. As intervenções nos recreios não devem ser de caráter obrigatório, porque condicionam as opções das crianças nesse espaço. Podemos sugerir alternativas no sentido de aumentar o seu repertório de jogo e potenciar, se possível, as interações. Podemos agir como moderadores, se as crianças assim o entenderem e nos solicitarem. 
Legitimamente, as crianças que não participaram na intervenção justificaram-no afirmando que preferem as suas brincadeiras com os seus amigos, pois, acima de tudo, o recreio providencia às crianças oportunidades para desenvolverem amizades e competências sociais (Navarro, 2012; Ramstetter et al., 2010).

Diversos estudos realçam a falta de movimento na idade infantil (Moral, 2018; Rodríguez-Fernández et al., 2018; Solís \& Borja, 2019; ZuritaOrtega et al., 2018), o que pode provocar prejuízos nestas idades (GigireyVilar et al., 2018; OMS, 2010; Ruvalcaba et al., 2018).

As crianças demonstraram envolver-se mais em jogos de movimento, daí que consideremos este como um dos efeitos positivos da intervenção efetuada. Tal como nos é confirmado por Serra e Serra (2007), as crianças ao longo do tempo aumentaram, consideravelmente, a prática de jogos locomotores, revelando que se envolvem em práticas bastante ativas no recreio.

Julgamos premente este tipo de intervenções, que potenciem a prática de diversos jogos nos recreios das escolas e, simultaneamente, a criação de condições para que as crianças possam praticar os seus jogos em segurança e com prazer. Como sabemos, atualmente, é nos recreios que as crianças realizam as suas atividades de forma "livre" e estes momentos são uma boa oportunidade para descobrirem novas atividades que lhes deem prazer e as motivem para as práticas de movimento (Stellino et al., 2010). As crianças têm necessidade de movimento e gostam de o fazer; no entanto, como nos confirma Levin (2012), é necessário perceber a melhor forma de promover o jogo junto das crianças, pois a sua ausência ou decréscimo pode ter consequências desastrosas nas suas vidas.

As crianças têm necessidades diferentes de jogo, pelo que quando se organiza uma intervenção, ou até mesmo quando se projeta um recreio de uma escola, é necessário ter em conta estas diferenças: criar espaços de jogo adequados a cada faixa etária, disponibilizar materiais fixos e móveis, e dar a conhecer às crianças jogos adequados às suas necessidades de movimento.

\section{LIMITAÇÕES DO ESTUDO E CONSIDERAÇÕES FINAIS}

O facto de a nossa intervenção ter tido a duração de apenas três semanas poderá ser o motivo pelo qual as nossas crianças não tiveram tempo de consolidar a prática de alguns dos jogos do dia a dia. No entanto, consideramos positivo o facto de alguns dos jogos terem permanecido como preferidos no recreio, passado tanto tempo, e tendo em conta a duração da aplicação da intervenção, que nos permitiu perceber que os jogos com regras e em grande grupo são os que as crianças gostam mais de realizar, que exigem uma ajuda na organização e moderação por um adulto, ainda que a sua presença se deseje mais informal.

Com base nos resultados do estudo, são estabelecidas as seguintes conclusões:

- Foram os rapazes que mais participaram na intervenção, no entanto as raparigas foram mais constantes na sua participação, sendo as crianças dos $1^{\mathrm{o}}$ e $2^{\mathrm{o}}$ anos de escolaridade as que mais se envolveram e participaram na intervenção. 
- As crianças gostam de participar nos jogos para aprender outros novos e para brincar com outros rapazes e raparigas.

- As crianças que preferem não participar nos jogos dizem que gostavan mais de realizar as suas brincadeiras com os seus amigos.

- Os jogos preferidos dos rapazes são os jogos de regras e, das raparigas, os jogos populares, facto que se verifica quando analisamos o ano de escolaridade, já que são as crianças mais velhas quem prefere os jogos de regras e as mais novas os jogos populares.

Acreditamos que ainda há muito por fazer quanto à diversidade de jogo que hoje se observa nas escolas. Devemos criar oportunidades (através de programas de intervenção, supervisão ajustada às necessidades da criança, adequação dos espaços de jogo e dos materiais existentes no recreio) para que as crianças conheçam e possam pôr em prática a maior diversidade de jogos possível no recreio. Só assim poderão explorar o seu "vocabulário" motor, na interação com outras crianças, potenciando as suas capacidades motoras e sociais durante os jogos com os seus pares.

\section{REFERÊNCIAS}

Artavia-Granados, J. M. (2014). El papel de supervisión del personal docente durante el desarrollo del recreo escolar. Revista Educación, 38(2), 19-36. https://doi.org/10.15517/revedu.v38i2.15259

Bodrova, E., \& Leong, D. (2005). The importance of play: Why children need to play. Early Childhood Today, 20(3), 6-7.

Bogdan, R., \& Biklen, S. (2003). Investigação qualitativa em educação: Uma introdução à teoria e aos métodos. Porto Editora.

Carbonell, T., Antoñanzas, J. L., \& Lope, A. (2018). La educación física y las relaciones sociales en educación primaria. Revista INFAD de Psicología, 2(1), 269-282. https://doi.org/10.17060/ijodaep.2018.n1.v2.1225

Castillo-Rodríguez, G., Picazo-Córdoba, C. C., \& Gil-Madrona, P. (2018). Dinamización del recreo como resolución de conflictos y participación en actividades físico-deportivas. Revista Electrónica Educare, 22(2), 1-22.

Delgado, I. (2011). El juego infantil y su metodología. Madrid, Espanha: Paraninfo.

Esteve, J. M. (2008). El repte de l'escola del segle XXI. Centre Integrat Jacint Verdaguer de Sant Sadurní d'Anoia. Revista Escola Catalana, 43(450), 26-28.

Farenzena, R., Costa, P., Pereira, V., \& Pereira, B. O. (2012). Bullying escolar: Descrição de um projeto de intervenção. In B. Pereira, A. Silva, \& G. Carvalho (Coords.), Atividade física, saúde e lazer. O valor formativo do jogo e da brincadeira (pp. 119-127). Centro de Investigação em Estudos da Criança da Universidade do Minho.

Fortin, M. (2006). Fondements et étapes du processus de recherche. Chenelière Education.

Fructuoso, M. R. (2016). El patio del recreo, un espacio de desigualdad entre niños y niñas. Publicaciones Didácticas, 74, 617-632.

Gallardo, J. A., \& Gallardo, P. (2018). Teorías sobre el juego y su importancia como recurso educativo para el desarrollo integral infantil. Revista Educativa 
Hekademos, 24, 41-51.

García-Lastra, M. (2013). Educar en la sociedad contemporánea. Hacia un nuevo escenario educativo. Convergencia, Revista de Ciencias Sociales, 20(62), 199-220.

Gigirey-Vilar, A., Rodríguez-Fernández, J. E., \& Ramos-Vizcaíno, A. (2018). Conductas psicosociales asociadas a la obesidad infantil observadas por el alumnado de educación primaria en las clases de educación física. Trances: Revista de Transmisión del Conocimiento Educativo y de la Salud, 10(2), 217-236.

Jover, G., Camas, L., Martin-Ondarza, P., \& Sánchez-Serrano, S. (2018). La contribución del juego infantil al desarrollo de habilidades para el cambio social activo. Recuperado de https://ciudadesamigas.org/wp-content/ uploads/2018/11/\%E2\%80\%9CLa-contribucio\%CC\%81n-del-juego-infantil-aldesarrollo-de-habilidades-para-el-cambio-social-activo\%E2\%80\%9D.pdf

Lester, S., \& Russell, W. (2011). El derecho de los niños y las niñas a jugar. Paises Bajos: Fundación Bernard van Leer. Recuperado de http://www.de0a18.net/ pdf/doc_drets_5_elderecho.pdf

Levin, D. (2012). Changing times, changing play: Why does it matter?.

Exchange, 207, 58-62.

López-Ros, V., \& Eberle, T. (2003). Utilizar los juegos para aprender a resolver conflictos. Tándem. Didáctica de la Educación Física, 10, 41-51.

Martín-Acosta, F., \& Escaravajal, J. C. (2019). Análisis bibliográfico sobre los programas de recreos activos. Revista Iberoamericana de Ciencias de la Actividad Física y el Deporte, 8(1), 125-135. https://doi.org/10.24310/riccafd.2019.v8i1.5790

Martín-Solbes, V. M., \& Ruiz-Galacho, S. (2018). La educación intercultural para una sociedad diversa. Miradas desde la educación social y la reflexión ética. Revista de Educación Social, 27, 36-47.

Massey, W. V., Stellino, M. B., Mullen, S. P., Claassen, J., \& Wilkison, M. (2018). Development of the great recess framework-observational tool to measure contextual and behavioral components of elementary school recess. BMC Public Health, 18, 394-405. https://doi.org/10.1186/s12889-018-5295-y

Méndez-Giménez, A. (2016). Centros escolares promotores de actividad física. Tándem: Didáctica de la Educación Física, 52, 4-6.

Meneses, M., \& Monge, M.A. (2001). El juego en los niños: Enfoque teórico. Revista Educación, 25(2), 113-124. https://doi.org/10.15517/revedu.v25i2.3585

Moral, L. (2018). Nivel de actividad física cardiosaludable en educación física en educación primaria: Expectativas y algunas evidencias. Sportis. Scientific Journal of School Sport, Physical Education and Psychomotricity, 4(1), 95-110. https:// doi.org/10.17979/sportis.2018.4.1.2017

Navarro, A. (2012). Actividad física en el recreo: Una buena oportunidad para educar. Foro Aragón, 5, 42-45.

Olweus, D. (1993). Bullying at school: What we know and what we can do. Blackwell Publishing.

Organización Mundial de la Salud. (2010). Sobrepeso y obesidad infantiles. Recuperado de https://www.who.int/dietphysicalactivity/childhood/es/

Otálvaro, S. J. (2011). El juego en la dimensión infantil: Aprendizaje e intersubjetividad. Revista de Educación \& Pensamiento, 18, 24-33.

Pereira, B. (2001). A violência na escola: Formas de prevenção. 
In B. Pereira \& A. P. Pinto (Coords.), A escola e a criança em risco: Intervir para prevenir (pp. 7-30). Asa.

Pereira, B. (2008). Para uma escola sem violência. Estudo e prevenção das práticas agressivas entre crianças. Lisboa, Portugal: Fundação Calouste Gulbenkian e Ministério da Ciência e Tecnologia.

Pereira, B., Neto, C., \& Smith, P. (1997). Os espaços de recreio e a prevenção do bullying na escola. In C. Neto (Ed.), Jogo e desenvolvimento da criança (pp. 238-257). Lisboa, Portugal: Edições FMH - Universidade Técnica de Lisboa.

Pereira, B., Silva, M., \& Nunes, B. (2009). Descrever o bullying na escola: Estudo de um agrupamento de escolas no interior de Portugal. Revista Diálogo Educacional, 9(28), 455-466. https://doi.org/10.7213/rde.v9i28.3169

Pereira, V., Condessa, I., \& Pereira, B. (2017). Educador em ação no recreio escolar: Formar para (inter)agir. In J. Airton Júnior (Org.), Conhecimentos do professor de educação física escolar (pp. 622-653). Editora da UECE.

Pereira, V. S., Rodríguez-Fernández, J. E., Pereira, B., \& Condessa, I. (2018). Os jogos das crianças nos recreios das escolas do $1 .^{\circ}$ ciclo do ensino básico do norte de Portugal. Movimento, 24(3), 859-874.

https://doi.org/10.22456/1982-8918.76335.

Ramstetter, C., Murray, R., \& Garner, A. (2010). The crucial role of recess in schools. Journal of School Health, 80, 517-526. https://doi. org/10.1111/j.1746-1561.2010.00537.x

Rimaicuna, M. I. (2014). Programa de juegos de interacción social para estimular el control de las conductas agresivas en primaria. Revista de Investigación y Cultura, 3(2), 43-52.

Rodríguez-Fernández, J. E., Gigirey-Vilar, A., \& Ramos-Vizcaíno, A. (2018). Análisis de los hábitos alimentarios y de actividad física en estudiantes gallegos de educación primaria. Sportis. Scientific Journal of School Sport, Physical Education and Psychomotricity, 4(3), 508-526. https://doi.org/10.17979/sportis.2018.4.3.3398

Rodríguez-Fernández, J. E., Pereira, V., Pereira, B., \& Condessa, I. (2019). Análisis de la interacción entre pares en los recreos de $1 .^{\circ}$ ciclo de enseñanza básica en Portugal. Retos, 36, 97-102.

Ruvalcaba, J. C., Hernández, J., García, J. R., Lozano, A., Morales, L. I., Hernández, M. S., Islas, I., Rivera, M., Reynoso, J. (2018). Factores desencadenantes de obesidad infantil, un problema de salud pública. Journal of Negative \& No Positive Results, 3(8), 614-626. https://doi.org/10.19230/jonnpr.2542

Serra, M., \& Serra, N. (2007). Actividades lúdico-motoras praticadas em meio rural por crianças do $1 .^{\circ}$ ciclo do EB. Mudanças verificadas entre 1992 e 2007. ESEG Investigação: Revista Científica da Escola Superior de Educação da Guarda, 1(4), 149-168.

Soares, N. (2006). A investigação participativa no grupo social da infância. Currículo Sem Fronteiras, 6(1), 25-40.

Soares, N., Sarmento, M., \& Tomás, C. (2005). Investigação da infância e crianças como investigadoras: Metodologias participativas dos mundos sociais das crianças. Nuances: Estudos sobre Educação, 12(13), 49-64. https://doi.org/:10.14572/ nuances.v12i13.1678

Solís, P., \& Borja, V. (2019). Niveles de actividad física y sedentarismo en escolares de $3 .^{\circ}$ y $4 .^{\circ}$ de educación primaria. Revista EmásF, 10(56), 119-131.

Stellino, M., Sinclair, C., Partridge, J., \& King, K. (2010). Differences in 
children's recess physical activity: Recess activity of the week intervention. Journal of School Health, 80(9), 436-444. https://doi.org/10.1111/j.1746-1561.2010.00525.x Wickstrom, R. (1977). Fundamental motor patterns. Lea \& Febiger.

Zurita-Ortega, F., Ubago-Jiménez, J. L., Puertas-Molero, P., González-Valero, G., Castro-Sánchez, M., \& Chacón-Cuberos, R. (2018). Niveles de actividad física en alumnado de educación primaria de la provincia de Granada. Retos, 34, 218-221.

i Universidade de Santiago de Compostela, Departamento de Didácticas Aplicadas, Área de Didáctica da Expresión Corporal, España. https://orcid.org/0000-0002-1101-5377

ii Universidade do Minho, Centro de Investigação em Estudos da Criança (CIEC), Portugal. https://orcid.org/0000-0001-8201-936X

iii Universidade dos Açores, Faculdade de Ciências Sociais e Humanas (FCSH), Centro de Investigação em Estudos da Criança (CIEC), Portugal. https://orcid.org/0000-0003-2868-0469

iv Universidade do Minho, Instituto de Educação, Centro de Investigação em Estudos da Criança (CIEC), Portugal. https://orcid.org/0000-0003-4771-9402

Toda a correspondência relativa a este artigo deve ser enviada para:

José Eugenio Rodríguez-Fernández

Universidade de Santiago de Compostela, Facultade de Ciencias da Educación

Avda. Xoán XXIII, s/n. 15782

Santiago de Compostela, A Coruña, España

geno.rodriguezausc.es

Recebido em 21 de julho de 2019

Aceite para publicação em 18 de março de 2020 


\title{
Evaluation of an intervention program in schools:
} Learn through play

\begin{abstract}
In the school context, playtime is one of the most favorable moments for the accomplishment of play and free activities, voluntarily practiced, and, consequently, for the improvement of social relationships and of the practice of physical activity. In order to know the students' perception in terms of the diversity of play and of the interactions that occur at the playground, a mixed-methodology quasi-experimental study was designed, with a proposal of intervention through the game, in wich 161 students, aged 6 to 10 years, from an elementary school in the north of Portugal participated. For the data collection, an ad hoc questionnaire was preferably used, as well as field notes and video recordings. The results shows us a high participation in the proposal for reasons of interest and attractiveness, especially in boys; games with rules and in a large group are prefered by both genders; likewise, it is in these inter-gender relations that there is a bigger increase, especially in the students of the last year. Playful intervention programs should be promoted to create practical opportunities and to diversify the type of play practiced by students at school.
\end{abstract}

Keywords: Playtime; Social interactions; Games;

Elementary school 
Evaluación de um programa de intervención em las escuelas: Aprender a través del juego

\section{RESUMEN}

Dentro del contexto escolar, el recreo es uno de los momentos más favorables para la realización de juegos y actividades de forma libre y voluntaria y, consecuentemente, para la mejora de las relaciones sociales y de la práctica de ejercicio físico. Con el objetivo de conocer la percepción del alumnado en cuanto a la diversidad de juegos practicados en el recreo y de las interacciones que allí ocurren, se diseñó un estudio cuasi-experimental de metodología mixta, con una propuesta de intervención a través del juego, en el que participaron 161 alumnos, de 6 a 10 años, de una escuela básica del norte de Portugal. Para la toma de datos se empleó preferentemente el cuestionario, además de notas de campo y grabaciones en video. Los resultados muestran una alta participación en la propuesta por motivos de interés y atractividad, sobre todo en los niños, siendo que los juegos con reglas y en grande grupo son preferidos por ambos géneros; asimismo, es en estas relaciones intergénero en las que hay un mayor aumento, sobre todo en el alumnado de último año Se deben promover programas de intervención lúdicos en el recreo para crear oportunidades prácticas y diversificar la tipología de juegos practicados por el alumnado en la escuela.

Palabras clave: Recreo; Interacciones sociales; Juegos; Escuela básica. 


\section{ANEXO \\ QUESTIONÁRIO “IDENTIFICAÇÃO DAS ATIVIDADES E \\ INTERAÇÕES DAS CRIANÇAS NOS RECREIOS”}

IDENTIFICAÇÃO

Qual é o ano de escolaridade que frequentas?

$1^{\circ} 2^{\circ} \quad 3^{\circ} \quad 4^{\circ}$

Quantos anos tens?

És rapaz $\square \quad$ ou rapariga $\square$ ?

Quantos irmãos tens?

INTERVENÇÃO

Participaste em jogos no recreio nas duas últimas semanas?

Sim $\square \quad$ Não

Porquê?

Qual foi o jogo em que mais gostaste de participar?

Durante esses jogos, brincaste com rapazes/raparigas com quem não costumavas brincar?

Sim $\square \quad$ Não

Gostaste de jogar com esses/as rapazes/raparigas?

Sim $\square \quad$ Não

Porquê? 